\title{
LA-6217-MS
}

Informal Report

\section{Development of Thin Shell Equations for Reactor Subassembly Dynamics}

by

\author{
G. P. DeVault \\ P. J. Blewett
}

UC-79p

Reporting Date: January 1976

Issued: February 1976 
In the interest of prompt distribution, this report was not edited by the Technical Information staff.

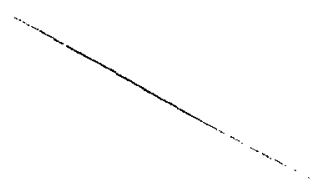

Work suoported by the Office of Nuciear Safety, Division of Reactor Developmeni and Demonstration, U.S. Energy Research and Development Administration.

Printed in the United States of Americ. Available from National Technical Information Seivice

U.S. Department of Cominerce 5285 Port Royal Road Springfield, VA 22151

Price: Printed Copy \$4.50 Microfiche \$2.25

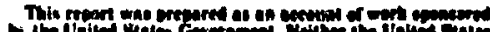

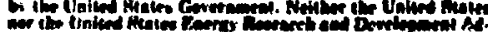

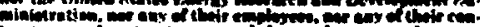

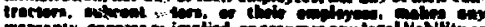

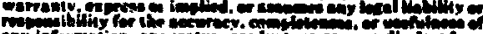

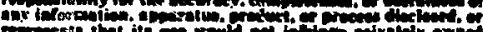
rewler. 


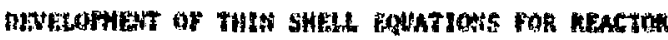

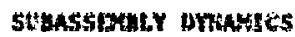

by

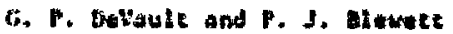

\section{A Astmact}

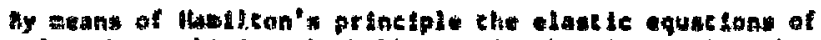

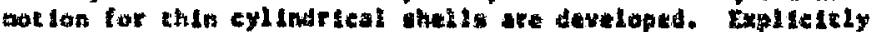

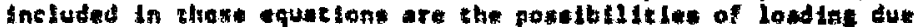
to interiog proanure pulges and co phermal seresuse. A cate

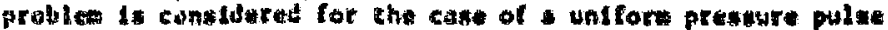

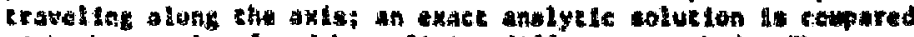

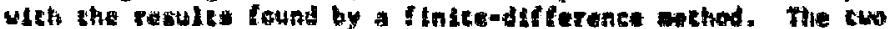

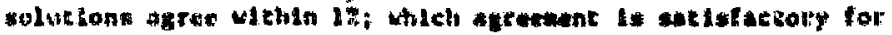
preture purpasess.

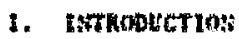

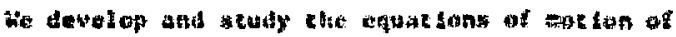

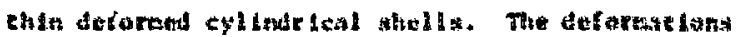

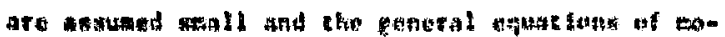

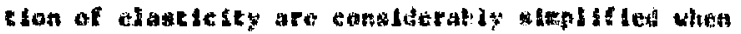
applled to chan ahelis.

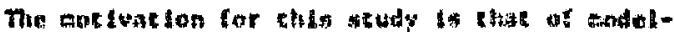

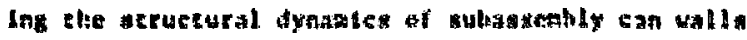
for asgumed ctore distupelve aceldunen af a liqute

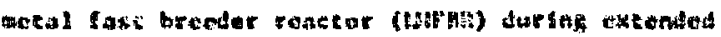

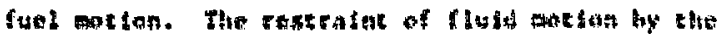

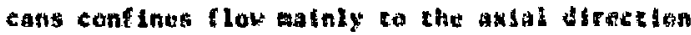

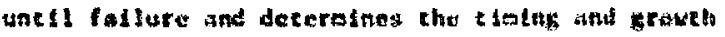

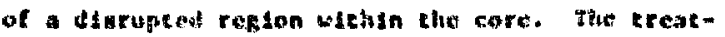

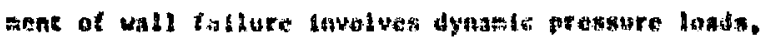

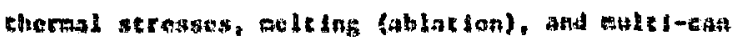
Intwrace tons.

The forma: 1 ate Alscusad hate has coreain aduan-

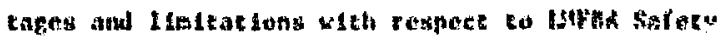
Research in les curreat torn. The enzhod ertises

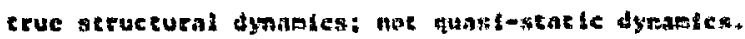

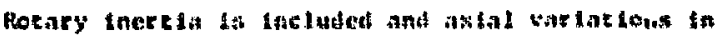
properefes are allowed. Tite clast te rexpans of clie can wall co dymanic shermal neranses and preksurd loading can bo campled. Feaeures wall wre cur-

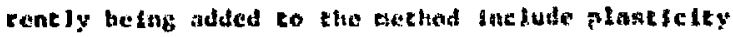

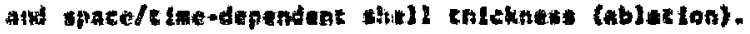

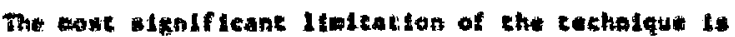

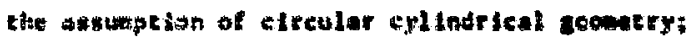

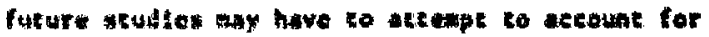

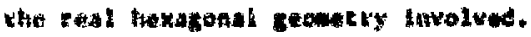

He consifer clased cirsular chlindical ehta

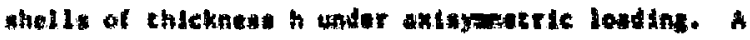

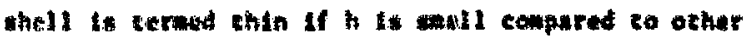

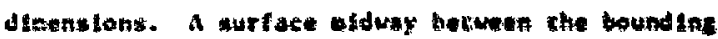

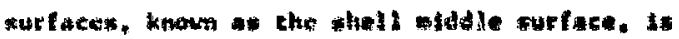

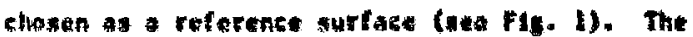

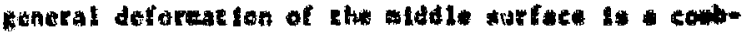

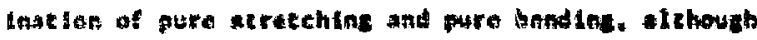

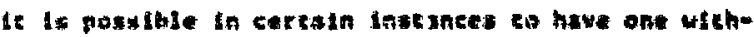

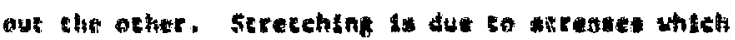
tre riste co forcen which art on an lawath of the shell in a difection congential te the midele wurtact

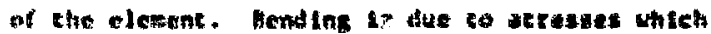
easge ehangeg th the curvature of the fodle wrtace,

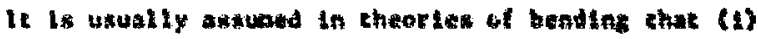

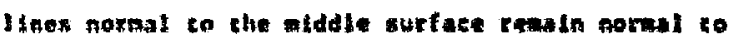

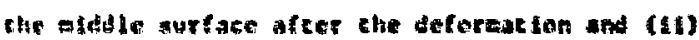

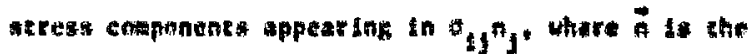
normal vector to the cyldudricat surfacan. can be

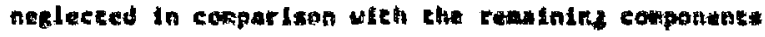
of che seress censor. The lacedr the ce the face 


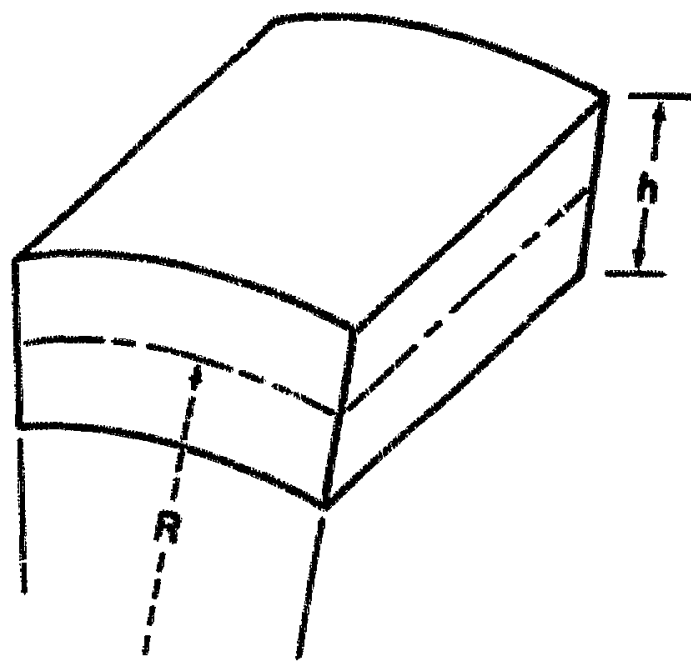

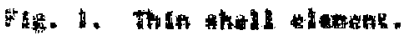

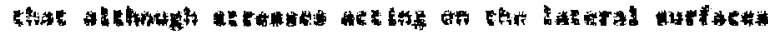

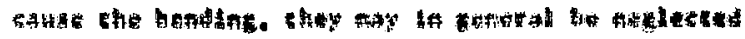

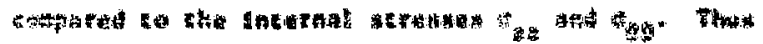

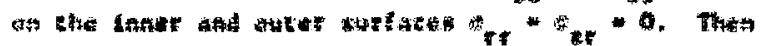

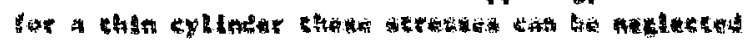

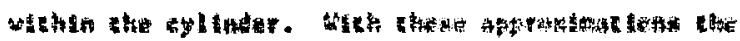

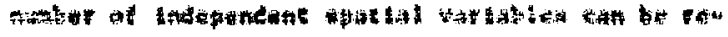

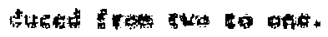

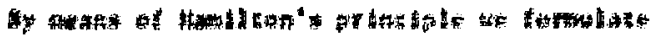

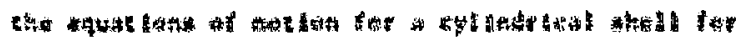

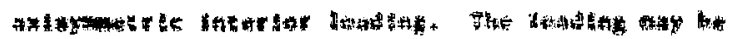

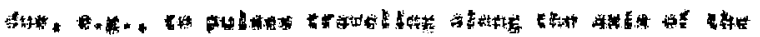

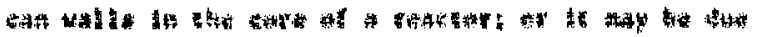

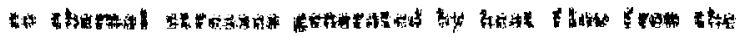

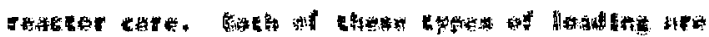

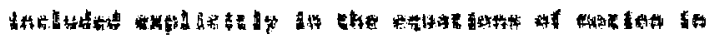

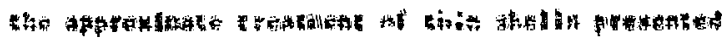
sto

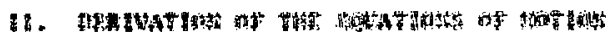

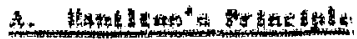

7.

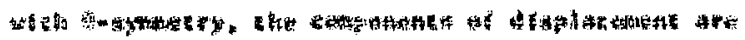

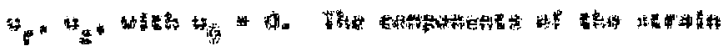

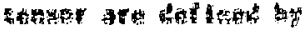

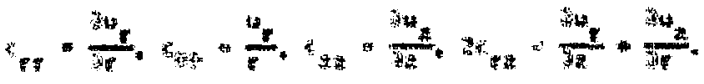

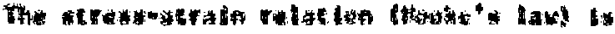

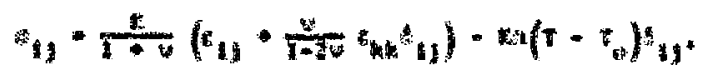

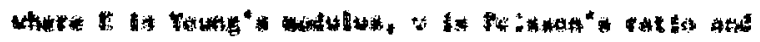

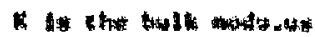

$+\frac{x}{11-30 \%}$

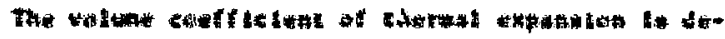

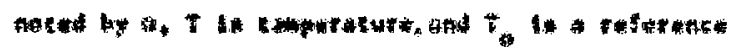

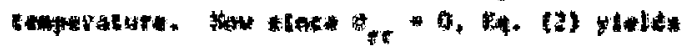

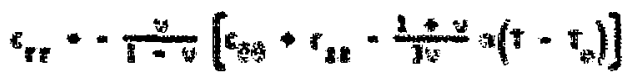

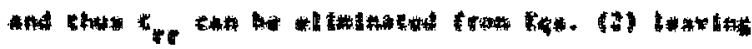

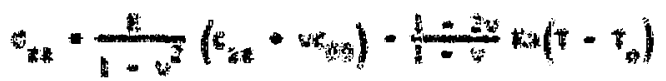

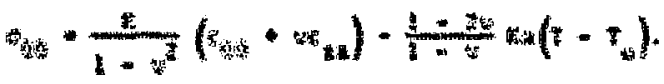

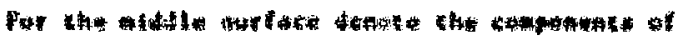

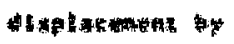

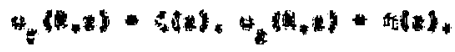

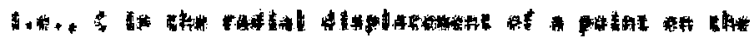

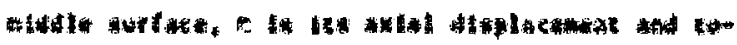

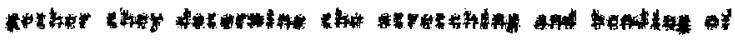

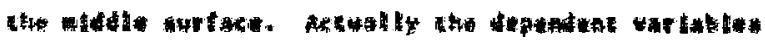

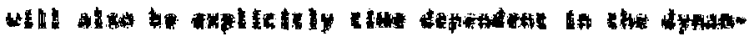

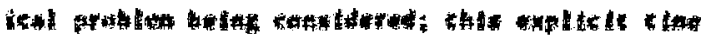

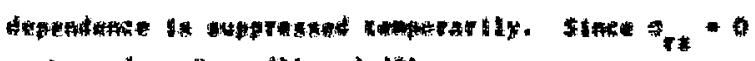

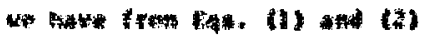

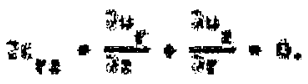

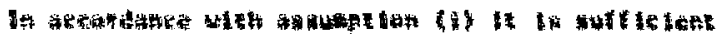
Fin

$\frac{x^{2}+4}{3 x}=-4$ 


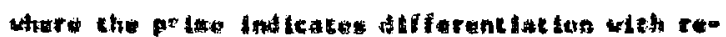
hater to 2. The walue iut th

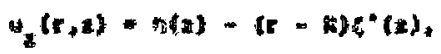

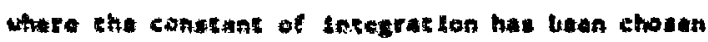

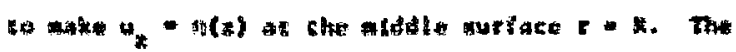

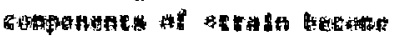

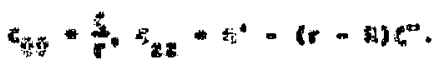

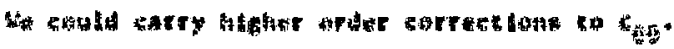

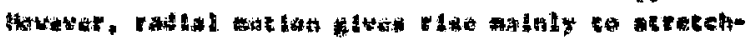

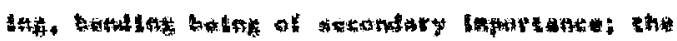

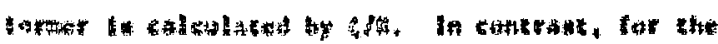

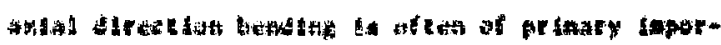

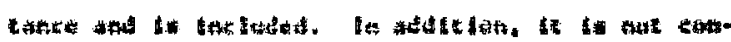

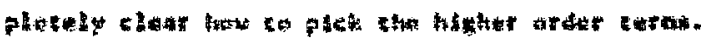

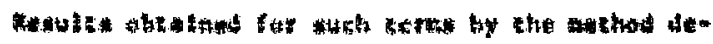

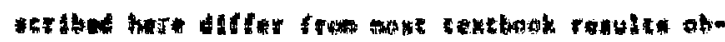

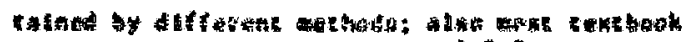

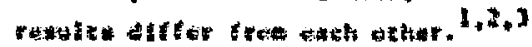

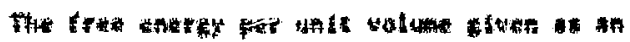

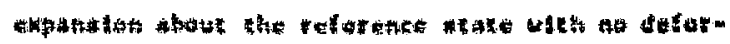

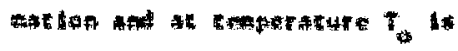

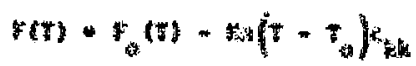

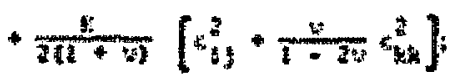

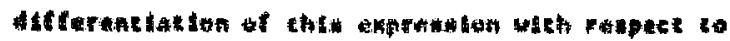

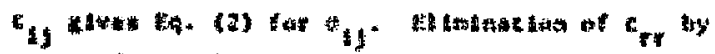
24

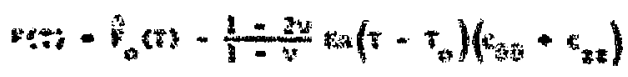

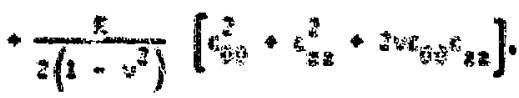

Mare

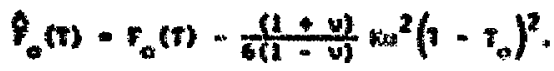

Thus with fig. (6) the tres eneroy trecenes

$$
\begin{aligned}
& F(t)=f_{0}(T)-\frac{1-2 v}{1-v} \cos \left(\tau-T_{0}\right)\left[\frac{\xi}{r}+n^{0}-(r-2) \xi^{n}\right] \\
& +\frac{E}{2\left(1-v^{2}\right)}\left[\frac{z^{2}}{r^{2}}+n^{0^{2}}+(r-n)^{2} s^{12}-2(x-n) n^{\prime} s^{\prime \prime}\right. \\
& \text { - } \left.2 v\left(\frac{5}{t} n^{\prime}-\frac{z-1}{r} 66^{*}\right)\right] \text {. }
\end{aligned}
$$

In ordar co form the Lesrange densey we also nend the hineste enarigy denstes

$$
\begin{aligned}
& \tau=(1 / 2)+\left(z^{2}+i^{2}\right) \\
& =(1 / 2) \cdot\left[z^{2}+\left(i-(r-n)^{4}\right)^{2}\right]
\end{aligned}
$$

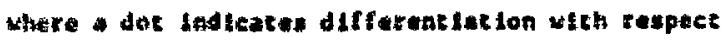

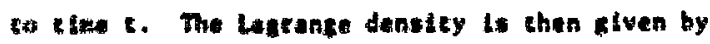

$c=7$

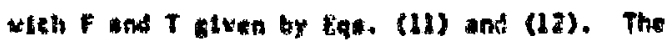

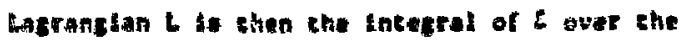
vollume of the exlinder.

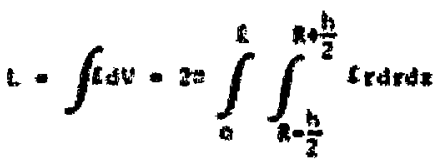

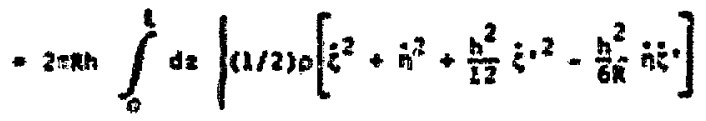

$$
\begin{aligned}
& -\frac{\varepsilon}{2\left(1-v^{2}\right)}\left[\frac{c^{2}}{n^{2}}+n^{2}+2 v \frac{k}{n^{2}} n^{*}+\frac{h^{2}}{12} \xi^{2}-\frac{h^{2}}{6 n} n^{*} \xi^{*}\right]
\end{aligned}
$$

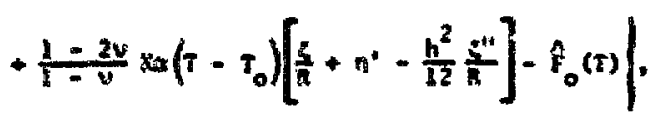

where $h^{2} / h^{2}$ has been netlected compared co unsty. Pullicon's prlaclple scates that the equations of wotion are daceminted by setcinc the vartation of the line integral of $L$ betueen $t$ sxed $t$ sees $t_{1}$ and $t_{2}$ aqual to the varieston of the sare line ineegral of 
the potential energy of the cylinder due to the external forcest acting on le* lateral aurface. The virtual displacesent on the varled pathe are for constant $z$ as well as constant $c$ and are taken to be sero at the and pointe $t_{1}$ and $t_{2}$. Thuse

$\delta \int_{t_{1}}^{t_{2}} t d t=-2 \pi R \int_{E_{1}}^{t_{2}} \int_{0}^{2}\left[p_{r} \delta t+p_{z} \delta \eta\right] d z d t$

where $\vec{p}$ to the extertul lotce per untt Iateral surface area. Cowbintng Eqa. (24) anc (15) and paxforwing the variation ve find
The variatione $6 f$ and $6 n$ are arbitrary and independent. The variational problew to solved by setting the coefficiente of 65 and on in the integrand of the second integral equal co zero and by cettins the corresponding boundary terme in the first integral eyual to zero. Thus the equatione of motion are

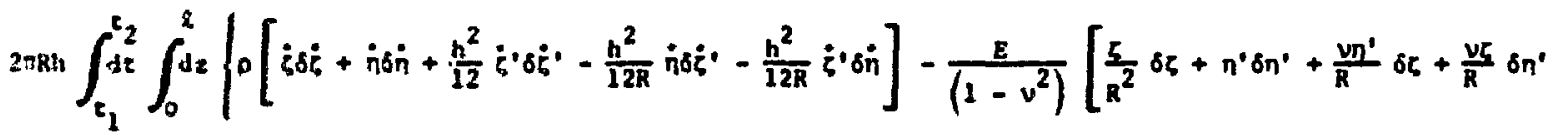

$$
\begin{aligned}
& \left.+\frac{h^{2}}{12} \zeta^{\prime \prime} \delta \tau^{\prime \prime}-\frac{h^{2}}{12 R} n^{\prime} \delta \zeta^{\prime \prime}-\frac{h^{2}}{12 R} \zeta^{\prime \prime} \delta n^{\prime}\right]+\frac{1-2 v}{1-v} k a\left(\tau-\tau_{0}\right)\left(\frac{\delta \zeta}{R}+\delta n^{\prime}-\frac{h^{2}}{12 R} \delta \zeta^{\prime \prime}\right) \\
& \left.+\left(\frac{F}{h} \delta \varepsilon+\frac{p_{z}}{h} \delta \eta\right)\right\}=0
\end{aligned}
$$

By ustag the face thac the vartation operation comweos with ordinary differenctation and by integracing by parce, che abuve reduces co

$$
\begin{aligned}
& \int_{t_{2}}^{E_{2}} d t\left[-\frac{h^{2}}{12} z^{\prime}+\frac{h^{2}}{12 R} \ddot{r}_{1}-\frac{t^{*}}{\left(1-v^{2}\right)}\left(-\frac{h^{2}}{12} c^{\cdots+}+\frac{h^{2}}{12 R} n^{\prime \prime}-(1+v) \frac{a}{3} \frac{h^{2}}{12 R} \tau^{\prime}\right)\right] \delta \zeta-\frac{E}{\left(1-v^{2}\right)}\left[\frac{h^{2}}{12} c^{\prime \prime}\right. \\
& \left.\left.-\frac{h^{2}}{\lambda 2 R} n^{\prime}+(1+v) \frac{a}{3} \frac{h^{2}}{12 R}\left(T-T_{0}\right)\right] \delta 5^{\prime}-\frac{E}{\left(1-v^{2}\right)}\left[n^{\prime}+v \frac{\zeta}{8}-\frac{h^{2}}{12 R} \zeta^{\prime \prime}-(1+v) \frac{\alpha}{3}\left(T-T_{0}\right)\right] \delta n\right\}\left.\right|_{0} ^{2}
\end{aligned}
$$

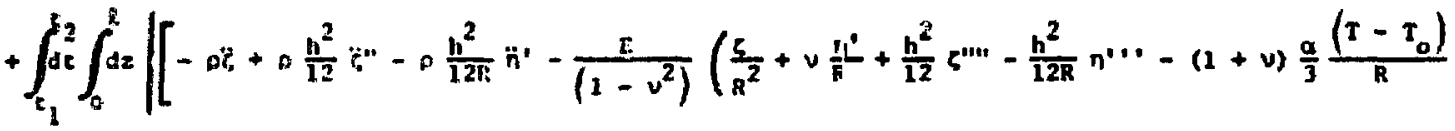

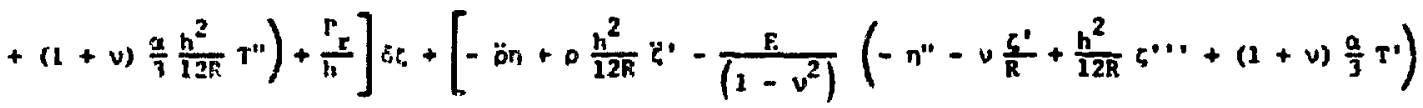

$$
\begin{aligned}
& \left.+\frac{2}{h}\right] \operatorname{lon} \mid=n
\end{aligned}
$$




$$
\begin{aligned}
& \rho \xi-\rho \frac{h^{2}}{12} \xi \cdot+\rho \frac{h^{2}}{12 R} \ddot{n}^{*}+\frac{E}{\left(1-v^{2}\right)}\left[\frac{\xi}{R^{2}}+v \frac{n^{\prime}}{R}\right. \\
& \cdot \frac{h^{2}}{12} \zeta^{\prime \prime \prime}-\frac{h^{2}}{12 R} \eta^{\cdots} \cdot(1+v) \frac{Q}{3} \frac{\left(\tau-\tau_{0}\right)}{R} \\
& \left.+(L+v) \frac{h^{2}}{12 R} \frac{\alpha}{3} T^{\prime \prime}\right]-\frac{P_{r}}{h} \\
& \rho \ddot{\eta}-\rho \frac{h^{2}}{12 \pi} \ddot{\zeta}^{\prime}-\frac{E}{\left(1-v^{2}\right)}\left[\eta^{n+v}+v \frac{\xi^{\prime}}{k}-\frac{h^{2}}{12 \pi} \zeta^{\cdots}\right. \\
& \left.-(1+v) \frac{a}{3} I^{\prime}\right]=\frac{P_{z}}{h}
\end{aligned}
$$

and the end conditions are

$$
\begin{aligned}
& \mid\left[\rho \ddot{\zeta}^{\prime}-\rho \frac{\ddot{z}}{\hat{p}}-\frac{E}{\left(1-v^{2}\right)}\left(t^{\prime} \cdots-\frac{\eta^{\prime \prime}}{B}\right.\right. \\
& \left.\left.+(1+v) \frac{a}{3} \frac{T^{\prime}}{R}\right)\right] \partial \zeta+\frac{E}{\left(1-v^{2}\right)}\left[\xi^{\prime \prime}-\frac{\eta^{\prime}}{R}\right. \\
& \left.+(1+w) \frac{\alpha}{3} \frac{\left(\tau-\tau_{0}\right)}{R}\right] \delta \zeta^{\prime}||_{0}^{2}=0 \\
& \int\left[n^{\prime}+v \frac{t^{2}}{\mathrm{R}}-\frac{\mathrm{h}^{2}}{12 \mathrm{R}} \zeta^{\prime \prime}\right. \\
& \left.-(1+v) \frac{\alpha}{3}\left(\tau-\tau_{0}\right)\right] \text { on }||_{0}^{i}=0 .
\end{aligned}
$$

Equations (16) and (17) represent a simplification of the probles in that there are two dependent variables and only one independent spatlal variable $z$. The end condition (18) is mainiy related to rotary inertia and to changes of curvature at the ends in planes contalning the axis. The end condition (19) with the afd of Eqs. (4) and (B) can be written as

$\left.\sigma_{z=2} \delta \pi\right|_{0} ^{2}=0$ where $\sigma_{22}$ is the average atress over a cross section of the cylinier.

\section{B. Discussion of End Condicione}

We can wistinguish vartous types of end conditions: Exapgle 1 . Suppose the cylinder is clapped at both ends. Then the toundary conditions to be inposed are

$$
\begin{array}{lll}
n(0)=0 & \zeta(0)=0 & \zeta^{\prime}(0)=0 \\
n(l)=0 & \zeta(l)=0 & \zeta^{\prime}(l)=0 .
\end{array}
$$

Since the variations of apecified condictone vanith, the end condition (18) and (20) are autonatically aciefied with these boundary condiefons. Exarple 2. The ende ate fixed but not clasped. Then

$$
\begin{array}{ll}
n(0)=0 & \zeta(0)=0 \\
n(1)=0 & \zeta(2)=0
\end{array}
$$

Here the variations $\delta \zeta^{\prime}(0)$ and $\delta \zeta^{\prime}(L)$ are arbierary and in order to satiafy the end condseions (18) and (20) tw additsonel condiesone are required

$\zeta^{\prime \prime}(z)-\frac{n^{\prime}(z)}{R}+(1+v) \frac{a}{3} \frac{\left(T(z)-\tau_{0}\right)}{R}=0$

at $z-0$ and $z=$ R. Exagle 3. The end at $z-0$ is clasped; the ocher end is tree. Then

$n(0)=0,5(0)-0,5^{\circ}(0)=0$.

llere the additional condit lons required are

$$
\sigma_{22}(R)=0
$$

$$
\begin{aligned}
\rho \xi^{\prime}(l) & -\rho \frac{\ddot{h}(l)}{R}-\frac{E}{\left(1-v^{2}\right)}\left[\zeta^{\prime \prime \prime}(l)-\frac{\eta^{\prime \prime}(l)}{R}\right. \\
& \left.+(1+v) \frac{L}{3} \frac{I^{\prime}(l)}{R}\right]=0
\end{aligned}
$$

$\zeta^{\prime \prime}(R)-\frac{n^{\prime}(R)}{R}+(1+v) \frac{Q}{3} \frac{\left(T(R)-T_{0}\right)}{R}=0$. 
Note that our probles was forsulated in such a way that the end conditions are such that the corresponding forces do no work on the cylinder. If we
By setting the deterninant of the soeffisiente of and $\eta_{0}$ equal to zero we find the diapersion relations

$$
\left|\begin{array}{cc}
-\omega^{2}+c_{1}^{2} k^{2} & 1 k w^{2} \frac{h^{2}}{12 \pi}-c_{1}^{2} 1 k\left(\frac{y}{R}+k^{2} \frac{h^{2}}{12 R}\right) \\
-1 w^{2} \frac{h^{2}}{12 k}+c_{1}^{2} 1 k\left(\frac{y}{R}+k^{2} \frac{h^{2}}{12 k}\right)-\left(w^{2}+n^{2} k^{2} \frac{h^{2}}{12}\right)+c_{1}^{2}\left(\frac{1}{g^{2}}+k^{4} \frac{h^{2}}{12}\right)
\end{array}\right|=0
$$

hat wished to Include end forces which do work and cause diaplacenents then we vould have had to have Included the arsociated variation in pocential energy in Mimileon' principle fust as we did for the applied laceral torces. These applted forces would have contributed to the end conditions (18) and (20), and analyses atsilar to those in the axaples above would show whet boundary consitions are nesesuary to acisfy glven probletes. For example, suppoce we wanted to tepose a tre-dependent force per unte crose-sectlonal area of tive cylinder $f_{2}(t)$ at $z=0$. Then and condition (20) would be modified to

$\sigma_{2 z}(R) \sin (t)-\left[a_{22}(0)-f_{z}\right] \operatorname{tn}(0)=0$.

\section{Diercrsion Relazions}

In order so investigate the noture of the equations of motion (16) and (17) we look at the dispersion relations. Set $T=T_{0}$ and $\vec{p}=0$ and take

$\zeta=5_{0} e^{1(k z-\omega t)} \cdot n=n_{0} e^{1(k z-\omega t)}$,

and substitute these into Eqs. (16) and (17). We obeain

$$
\begin{aligned}
& -\left(\omega^{2}+\omega^{2} k^{2} \frac{h^{2}}{12}\right) \zeta_{0}-1 k \omega^{2} \frac{n^{2}}{12 R} \eta_{0} \\
& +c_{1}^{2}\left[\frac{\zeta_{0}}{R^{2}}+1 k v \frac{\eta_{0}}{R}+k^{4} \frac{h^{2}}{12} \zeta_{n}+1 k^{3} \frac{h^{2}}{12 R} \eta_{0}\right]=0 \\
& -\omega^{2} \eta_{0}+1 k \omega^{2} \frac{h^{2}}{12 R} \zeta_{0} \\
& -c_{1}^{2}\left[-k^{2} \eta_{0}+i k v \frac{\zeta_{0}}{R}+1 k^{3} \frac{h^{2}}{12 R} \cdot \zeta_{0}\right]=0 .
\end{aligned}
$$

where

$c_{2}^{2}-\frac{E}{o\left(1-v^{2}\right)}$

There are two roote for $\omega^{2}$ and to ozder $t^{2}$ thet are

$w^{2}=\left\{\begin{array}{l}\frac{c_{1}^{2}}{R^{2}}\left(1+v^{2} k^{2} k^{2}\right) \\ c_{1}^{2}\left(1-v^{2}\right) k^{2}\end{array}\right.$

The flrse root correspond to andnly radial ouctllatione and the second root sorresponds to longlcudinsl waves. To see this, wbstitute the firse root into either of Eqt. (22). To lavat order in wave number one finda

$\eta_{0}=-1 k v R G_{0}$

or frae Eq. (21)

$\eta=\eta_{0} e^{l(k z-\omega t)}=-1 k v R \zeta_{0} e^{1(k z-\omega t)}=-v R \zeta^{\prime} \cdot$ Substicuting this reault into Eq. (16) yields

$$
\begin{aligned}
0 \ddot{\zeta}-p \frac{h^{2}}{12}(1+v) \zeta^{\prime \prime}+\frac{E}{\left(1-v^{2}\right)}\left[\frac{\zeta}{R^{2}}-v^{2} \zeta^{\prime \prime}\right. \\
+\frac{h^{2}}{12}(1+v) \zeta^{\prime \prime \prime \prime}-(1+v) \frac{a}{3} \frac{\left(T-T_{0}\right)}{R} \\
\left.+(1+v) \frac{h^{2}}{12 R} \frac{\alpha}{3} T^{\prime \prime}\right]-\frac{P_{\tau}}{h},
\end{aligned}
$$

which predicts mainly radial oscillations. 
Siellarly the second root of (23) when subwe:tuked into Eqs. (22) yiclds

$\zeta_{0}=-1 k A v n_{0}$

or $\operatorname{tros}(21)$

$r=\varepsilon_{0} e^{1(k 2-\omega t)}-\ldots$ lkRun $_{0} e^{1(k 2-u t)}=-$ RVn'.

Substitution of this result into Eq. (17) gives

$$
\begin{aligned}
& \Delta \ddot{n}+\rho \frac{h^{2}}{12} v \ddot{n} "-\frac{E}{\left(1-v^{2}\right)}\left[\left(1-v^{2}\right) n^{\prime \prime}\right. \\
& \left.+\frac{h^{2}}{12} u n^{\prime \prime \prime}-(1+v) \frac{q}{3} \tau\right]-\frac{p_{2}}{h}
\end{aligned}
$$

which predict: longltudinil waves traveling along the cyllnder with essentially the "bar" velocity $\sqrt{E / P}$ nodifled by sose dispersion.

The type of probles we wish to constder wili be that of a pressuro or a thermal pulse traveling along the cylinder ax1s. Thus we w11l be concerned minly with the type of motion predicted by Eq. (24). Furklucreore, the wotion will gosely be radial involving stretching of the middle surface and we will ignore those terws proportional to $\mathrm{h}^{2}$ which relate to pure beviling didd rolary incrila. Thus we have

$\zeta+c_{1}^{2}\left[\frac{\zeta}{R^{2}}-v^{2} \xi^{\prime \prime}-(1+v) \frac{a}{3} \frac{\left(T-T_{0}\right)}{R}\right]-\frac{p_{r}}{\rho h^{\prime}}$

Constatent with this equation we have

$$
\begin{aligned}
& u_{r}=\zeta \\
& u_{z}=-R v \zeta^{\prime} \\
& \varepsilon_{\theta \theta}=\frac{\zeta}{R} \\
& \varepsilon_{2 z}=-R v \zeta^{\prime \prime} \\
& E_{5 z}=-\frac{v}{1-v}\left[\frac{\zeta}{R}-R v \zeta^{\prime \prime}-\frac{1+\nu}{v} \frac{\alpha}{3}\left(T-T_{0}\right)\right] .
\end{aligned}
$$

It should be noted that $\mathrm{Eq}$. (26) gives the sape solution for the static case of a long cylinder with constant unifore internal pressire as does the thin sheil lielt of the colution of the exact equations of elasticity. The usual etaric equilibriue equation derived in textbooks ${ }^{3}$ differe from the atatic part of Eq. (26) and 1a derived on the asaupeion that the average force corresponding to $\sigma_{z 2}$ Is zero. This would be correct for stacte probleme of cylindera with finite length and no applied longleudinal forces at the endw. However, for dynanc problews with pulae traveling along the cylinder we would expece Eq. (26) to pertain as a pulse does not know of the finite length until reflection occurs.

In the next section we inveatigate the properties of Eq. (26) to see if it is adequate, once we allow for plastic deformaticn, for problems related to reactor safety.

\section{A TEST PROBLEY}

\section{A. Analve1c Solution}

We next consider a teat problem for Eq. (26) wherein an exact analyetc solution is compared with a computer fintte-difference solution. First it is conveniene to incroduce dimensionless variablea defined by

$$
\begin{aligned}
& \hat{t}=\frac{c_{1}}{R} t_{,} \hat{z}-\frac{1}{R U} z, \hat{\zeta}=\frac{1}{R} \zeta, \hat{T}-\hat{T}_{0} \\
& =(1+v) \frac{\alpha}{3}\left(T-T_{0}\right), \hat{P}_{T}=\frac{B}{D e_{1}^{2} h} P_{T} .
\end{aligned}
$$

Then Eq. (26) becomes, dropping the hats,

$$
\zeta+\zeta-\zeta^{\prime \prime}-\left(T-T_{0}\right)=P_{\tau^{*}}
$$

For $P_{r}$ we choose

$$
P_{r}=P_{0} s\left(t-\frac{z}{V}\right)
$$


where $P_{0} 18$ a constant and $S(t)$ 1a the unit step function

$s(t)=\left\{\begin{array}{l}0, t<0 \\ 1, t>0 .\end{array}\right.$

Thus (29) represents a step-function pressure pulae traveling along the axis of cylindrical tube with dimensionless velocity $V$. $V$ may be subeonic, sonic, or supersonic according to $0<v<1, v-1, v>1$, reapectively. Thia problen was cirosen becaune $1 t$ models reuctor subasseably cas wall elastc radis displacement for axial fuel wotion. The temperature is here taken to be uniform.

The Laplace tiansfore of $\zeta$ is defined by

$\bar{\zeta}(z, p)=\int_{0}^{\infty} d t e^{-p t} \zeta(z, t)$,

and the cransforms of Eqs. (28) and (29; yield

$p^{2} \bar{\zeta}+\bar{\zeta}-\bar{\zeta}^{\prime \prime}=\frac{P_{0}}{p} e^{-p z / v}$.

where for convergence of the transf urm $p$ must have a positive real part $E$. A solution of (II) is

$\bar{\zeta}=A e^{-\sqrt{p^{2}+1} z}+B e^{\sqrt{p^{2}+1}}=-\frac{P_{0}}{p} \frac{e^{-p z / v}}{p^{2}\left(\frac{1-v^{2}}{v^{2}}\right)-1}$.

The constants $A$ and $B$ are determined by the boundary condittons which we talce to be

$$
\begin{aligned}
& \zeta(\infty, t)=0 \\
& \zeta^{\prime}(0, t)=0 .
\end{aligned}
$$

$$
\begin{aligned}
& \text { Thus } \begin{aligned}
\bar{\zeta} & =\frac{v_{p_{0}}}{1-v^{2}} \frac{e^{-\sqrt{p^{2}+1}}}{\sqrt{p^{2}+1}\left[p^{2}-\frac{v^{2}}{1-v^{2}}\right]} \\
& -\frac{v^{2}}{1-v^{2}} \frac{p_{0}}{p} \frac{e^{-p z / v}}{\left[p^{2}-\frac{v^{2}}{1-v^{2}}\right]}
\end{aligned}
\end{aligned}
$$

The Inverse Lapluce eransfore is given by

$\zeta(z, t)=\frac{1}{2 \pi !} \int_{-1+\varepsilon}^{20+\varepsilon} d p e^{p t} \bar{z}(z, p)$

Constder firat the inverae crangfore $I_{1}$ of the decond tem In Eq. (32): it can be evaluated by realfue theory. There are three cases:

(1) $v<1$. There are three poter which lie on the raed axis at $\frac{-v}{\sqrt{1-v^{2}}}, 0, \frac{y}{\sqrt{1-v^{2}}} \cdot$ For $t>s / v$ the contour wust be closed in the left half-plene and the poles are enclased. For $t<z / V$ the contour wat be closed in the right half-plane and no poles are enclosed. Thus

$I_{1}=\left\{\begin{array}{l}P_{0} \mid 1-\cosh \left[\frac{v}{\sqrt{1-v^{2}}}(t-2 / v)\right], t>2 / v \\ 0, t<2 / U\end{array}\right.$

(11) $v>1$. The three poles now lin on the thaginary axis; the contour must be closed to the left for $z<v t$ and als three poles are enclosed. Thus

$I_{1}=\left\{\begin{array}{l}P_{0} \mid 1-\cos \left[\frac{v}{\sqrt{1-v^{2}}}(t-z / V)\right], t>I / V \\ 0, t<z / V\end{array}\right.$

(111) $v=1$. There is only one pole, at $p=0$, and

$I_{1}=P_{n} S(t-x)$.

Next we evaluate the Inverse transform of the first term in Eq. (32),

$I_{2}=\frac{v P_{0}}{1-v^{2}} \frac{1}{2 \pi 1} \int_{-1 \infty+\varepsilon}^{1+c t e} d p e^{p t} \frac{e^{-\sqrt{p^{2}+1}}}{\sqrt{p^{2}+1}\left[p^{2}-\frac{v^{2}}{1-v^{2}}\right]}$ 
This eam be wetcen ag a convolution aince

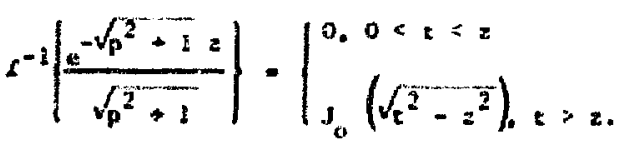

Jios ve have for the chree casea:

(t) $y<:$.

(11) $v: 1$.

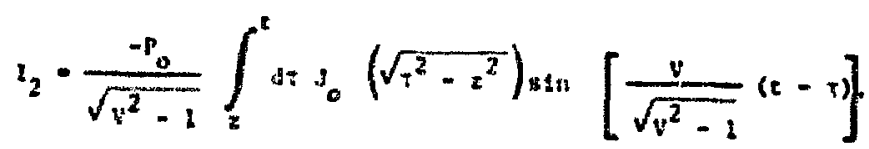

(111) $v=1$

$t_{2} \cdot-J_{0}\left(\sqrt{L^{2}-z^{2}}\right) s(c-2)$.

ay comining the above results, $5-I_{2}+I_{2}$, we huste:

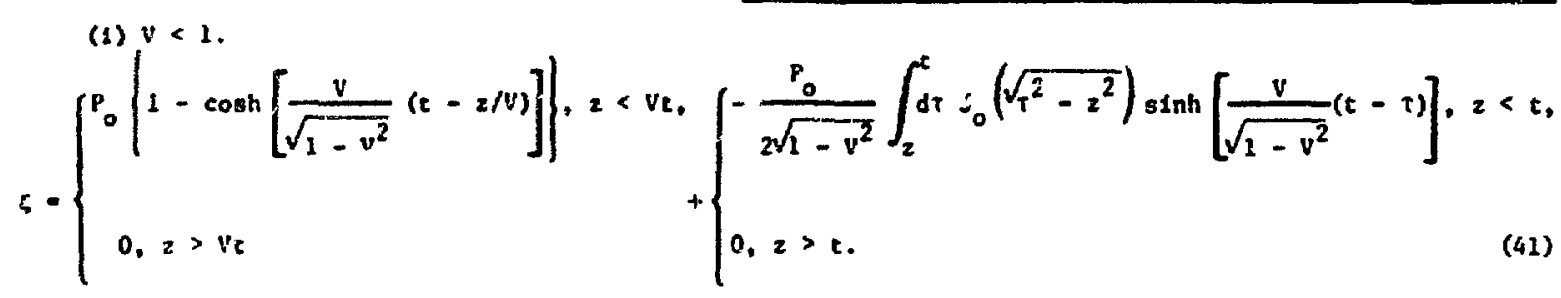
$\zeta=\left\{\begin{array}{l}P_{0}\left\{1-\cos \left[\frac{v}{\sqrt{1-v^{2}}}(t-z / v)\right], z<v t \quad\left[-\frac{P_{0}}{\sqrt{v^{2}-1}} \int_{\infty} d t J_{0}\left(\sqrt{\tau^{2}-z^{2}}\right) \sin \left[\frac{v}{\sqrt{v^{2}-1}}+(t-t)\right], z<t,\right.\right. \\ 0, z>v t,\end{array}\right.$ (111) $v=1$.

$\zeta=P_{0}\left[1-J_{0}\left(\sqrt{t^{2}-z^{2}}\right)\right] s(t-z)$. 
At cycle n $\zeta^{\prime \prime}$ was computed from,

$$
\begin{aligned}
\left(\zeta^{\prime \prime}\right)_{j}^{n} & =\left[\left(\frac{\Delta \zeta}{\Delta z}\right)_{j+1 / 2}^{n}\right. \\
& \left.-\left(\frac{\Delta \zeta}{\Delta z}\right)_{j-1 / 2}^{n}\right] /\left(z_{j+1 / 2}-z_{j-1 / 2}\right)
\end{aligned}
$$

where

$$
\begin{aligned}
\left(\frac{\Delta \zeta}{\Delta z}\right)_{j+1 / 2}^{n} & =\left(\zeta_{j+1}-\zeta_{j}\right)^{n} /\left(z_{j+1}-z_{j}\right) ;\left(\frac{\Delta \zeta}{\Delta z}\right)_{j-1 / 2}^{n} \\
& =\left(\zeta_{j}-\zeta_{j-1}\right)^{n} /\left(z_{j}-z_{j-1}\right)
\end{aligned}
$$

Thus $\zeta$ is centered at the $f^{\text {th }}$ grid point. With a suitable prescription for $P_{r}$ the right-hand side of (44), denoled as (RHS) ${ }_{j}^{n}$, is then evaluated for the $n^{\text {th }}$ cycle. $\zeta$ is then advanced in time by the following equations,

$$
\begin{aligned}
& \left(\frac{\Delta \zeta}{\Delta t}\right)_{j}^{n+1 / 2}-\left(\frac{\Delta \zeta}{\Delta t}\right)_{j}^{n-1 / 2}=(R H S)_{j}^{n}\left(t^{n+1 / 2}-t^{n-1 / 2}\right) \\
& (\zeta)_{j}^{n+1}-(\zeta)_{j}^{n}=\left(\frac{\Delta \zeta}{\Delta t}\right)^{n+1 / 2}\left(t^{n+1}-t^{n}\right)
\end{aligned}
$$

Use was made of the wONDY 4 lagrangtan code as a vehicle for Input and output and co provide a grid of 400 cells with $\Delta z=0.1$. The Lagranglan dynamics of WONDY was nullified and three problems were run with $V=1 / 2,1,2$. In each case a value of $P_{Y}=1$ was loaded Into those cells where

a. $\leq$ vt.

A constant time step of $\Delta t=0.08$ was chosen to satisfy the Courant condition, because the nondimenstonal sound speed is 1 unit.

The results of the calculations are shown in Figs. 2, 3, 4 for $V=1 / 2,1,2$, respectively. In each figure the continuous line is the difference solution and the asterisks denote the analytic solution. Computer proflles of $\zeta$ vis $z$ at time
Intervals of four units were taken so that we could waich the progress of the wave. Figures 2, 3, 4 show these profiles at times when the wave front is neer the end of the grid, $1 . e ., t=36,36$, and 16 respectively. In the $V=1$ case some $d$ ifficulty was encountered in resolving the high frequency oscillations fmmediately behind the wave front; for this case it was necessary to double the mesh to 800 cells with $\Delta z=0.05$ and a corresponding change In $\Delta t$ in order to produce agreement with the analytic solution. Apart from this difficulty the agreement between the difference solutions and the analytic solutions was at worst about $1 \%$ and often within 0.1\%. For our purposes this agreement is satisfactory.

\section{DISCUSSION}

A theory fot the dynamics of cylindrtcal elastic thin shells has been developed from Hamilton's principle. The resulting coupled equations of notion are further approximated, from an analysis of the dispersion relations, by a single equation of motion involv'ng only the radial disfiacement as dependent variable. Analytic solutions for the problem of an 1nterfor step pressure pulse traveling along the axis compare exceptionally well with fintte difference solutions. This agreement val1dates the finite difference scheme. Future studies will compare restilts from this approximate theory with those from the exact equations of elasticity to ascertain the class of problems for which the approximate theory is suitable. In addition the theory will be extended to Include plastic deformation, ablation, and fallure in order to treat LMPR structural dynamics.

\section{REFERENCES}

1. W. Flügge, Stresses in Shells (Springer-Verlag, New York, Heidelberg, Berlin, 1973), Chap. 5.

2. P. M. Ogibalov, Dynamics and Strength of She1ls (Israel Program for Sclentific Tranglations, Jerusalem, 1956), Chap. 2.

3. S. TImoshenko, Theory of Plates and Shells (McGraw-H111, New York, 1940), Chap. XI.

4. R. J. Lawrence and D. S, Meson, "WONDY IV - A Computer Program for One-Dimensional Wave Propagation with Rezoning," Sandia Laboratories report SC-RR-710284 (August 1971). 


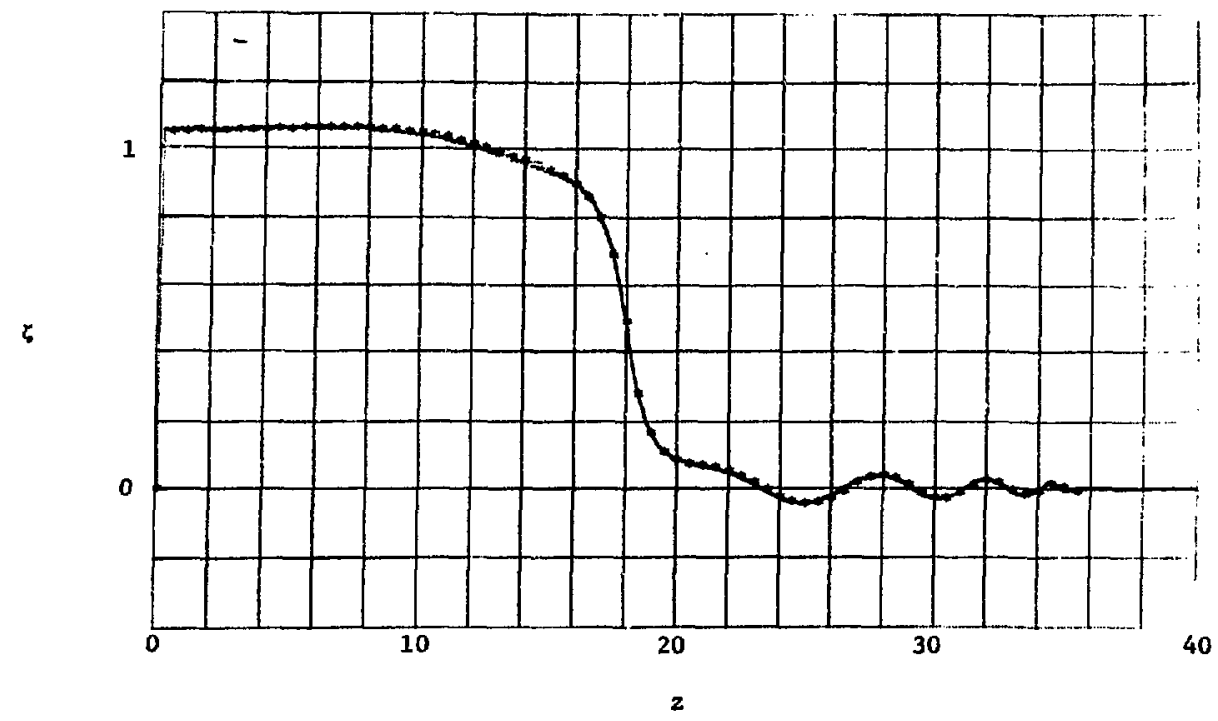

F18. 2. Radial displacement, $\zeta$, ys $z$ for subsonic case, $V=1 / 2$. The solid line shows the finite difference solution and asterisks depict the analytic solution for $t=36$.

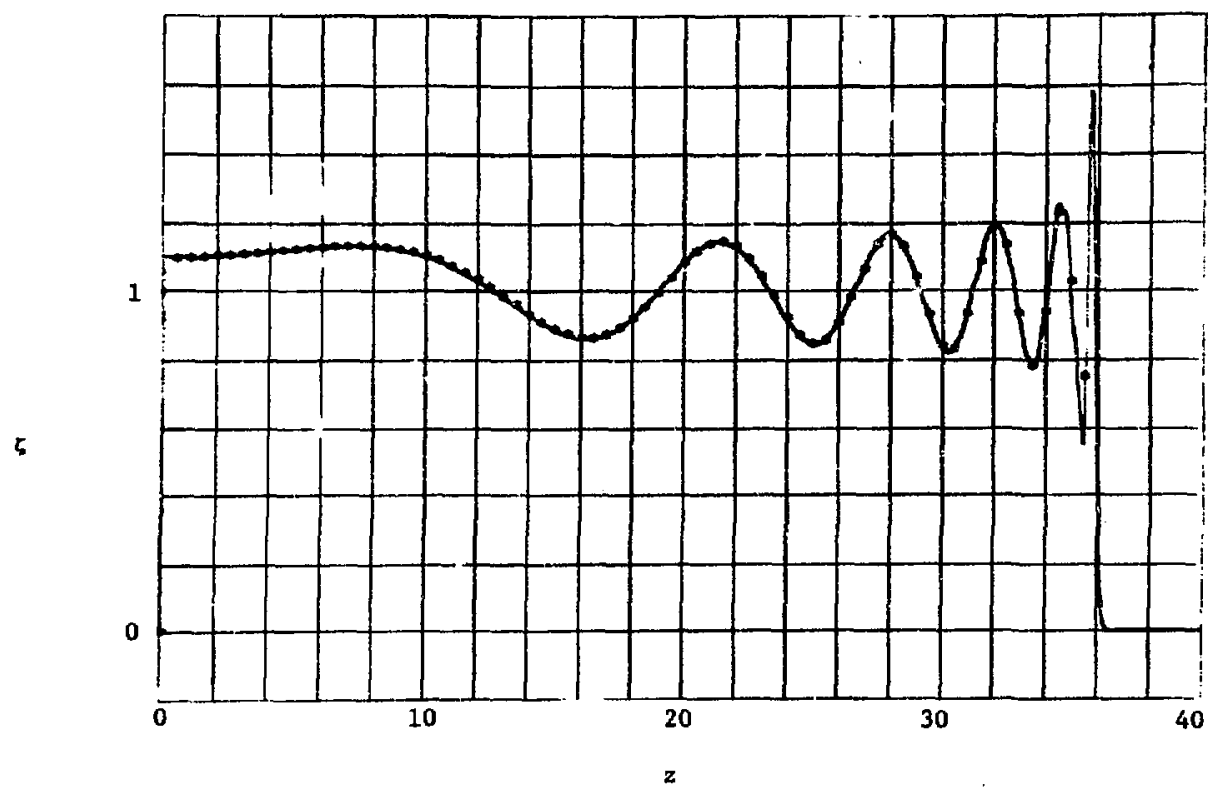

F18. 3. Radial displacement, $\zeta$, vo 2 for sonic case, V-1. The solld ine shows the fintte difference solution and asterisks depict the analytic solution for $t=36$. 


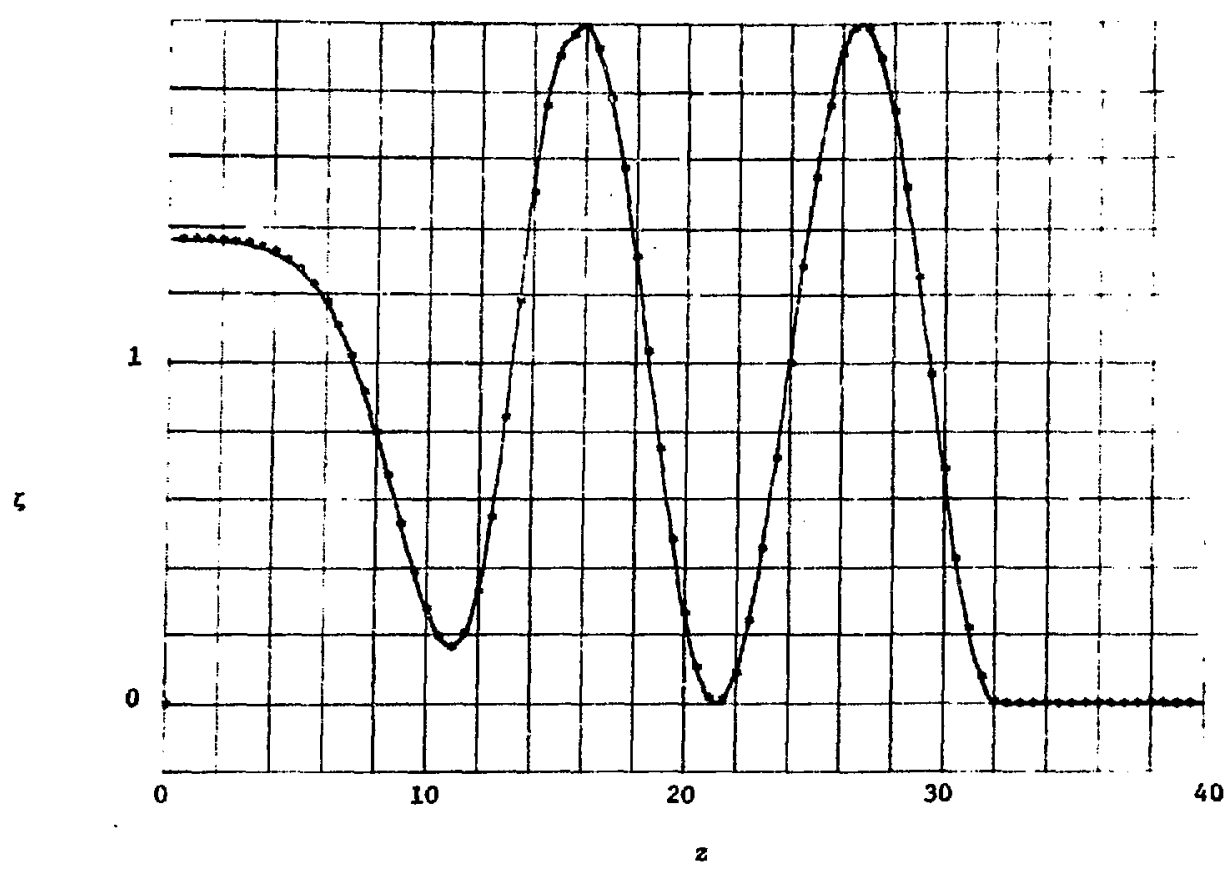

F18. 4. Radial displacement, 5 , vs $z$ for supersonic case, $V=2$. The solld J.Ine shows the finlte difference solution and asterloks deplat the analyric solution for $t=16$. 